\title{
Breast Fibroepithelial Neoplasm
}

National Cancer Institute

\section{Source}

National Cancer Institute. Breast Fibroepithelial Neoplasm. NCI Thesaurus. Code C40405.

A benign or malignant biphasic neoplasm that arises from the breast parenchyma. It is characterized by the presence of an epithelial and a mesenchymal (stromal) component. The typical examples are fibroadenoma and phyllodes tumor. 